\title{
Nonmedical use of prescription opioids: What is the real problem?
}

\author{
Mary Lynch MD
}

$\mathrm{C}$ ontroversies abound concerning the use and misuse of prescription opioid analgesics (POAs). It is important to further define the issue of what has come to be known as nonmedical prescription opioid use (NMPOU). This is exactly what Shield et al (1) have done in their article, 'Use and nonmedical use of prescription opioid analgesics in the general population of Canada and correlations with dispensing levels in 2009', published in the current issue of Pain Research $\mathcal{E}$ Management (pages 69-74). The key new findings are that the misuse of POAs "to get high" is $0.4 \%$, and that there is no association between the general use of POAs and the misuse of POAs.

A major strength of this article is that the questions used in the Canadian Alcohol and Drug Use Monitoring Survey (CADUMS) are presented clearly. This is critical to understanding the findings. In the CADUMS, NMPOU included individuals who acknowledged using their pain relievers more than they were supposed to, obtaining the pain reliever from a family member or friend, obtaining the medication from the Internet, from a pharmacist without a prescription or from any other source without a prescription. Nonmedical use also included using a pain reliever to get high. The CADUMS was one of the few surveys that enabled a clear distinction between using an opioid for pain relief versus for a recreational purpose (ie, to get high). The findings indicate that the prevalence of any use of POAs in Canada in 2009 was $19.2 \% ; 4.8 \%$ of respondents acknowledged NMPOU $(4.5 \%$ of men and $5.1 \%$ of women) and $0.4 \%$ indicated they had used the POA "to get high". Use of POAs to get high varied significantly across provinces but did not exhibit any difference according to age. There was no association between the amount of POA dispensed in a province and misuse or use to get high. These are important findings in a climate in which NMPOU has become a flashpoint in medicine, attracting significant media attention in a manner that has clouded the picture and placed individuals experiencing pain in jeopardy.

In understanding this problem, it is helpful to consider other studies examining NMPOU both in the general population and in our youth. The CADUMS is an excellent source of information for drug use in the general population 15 years of age and older. The most recent statistics, from the CADUMS 2011, reveal a significant decline in the use of POAs, to $16.7 \%$ from $20.6 \%$ in 2010 . The 2011 report did not separate the nonmedical use of opioids from other psychoactive pharmaceuticals (which include opioid pain relievers, stimulants, tranquilizers and sedatives) and found that 3.2\% of respondents who had used psychoactive pharmaceuticals reported "abusing" these drugs (ie, "to feel better, cope with stress or for any other reason"), and $0.3 \%$ of the population reported use of psychoactive pharmaceuticals to get high. This is a decrease from 2009 and, given the fact that this figure included all psychoactive pharmaceuticals, there has been a significant and notable decline in the abuse of POAs to get high (2).

There are several student drug use surveys performed in Canada. The Ontario Student Drug Use and Health Survey (3) found that $18 \%$ of students in grades 7 through 12 reported using an opioid pain reliever without a prescription in the past year. Use was higher in females $(20 \%)$ compared with males $(16 \%)$, and three-quarters had obtained the medication from home. The Alberta Youth Experience Survey 2008 (4), which included students in grades 7 through 12, reported that codeine was the prescription drug used most frequently without a prescription, with $15.5 \%$ reporting use in the past year and $22.1 \%$ reporting use without a prescription in their lifetime.

In the Atlantic provinces, the Student Drug Use Survey 2007 introduced an item asking, "In the past 12 months, have you taken pain killers (Percocet, Percodan, Tylenol 3, Dilaudid, OxyContin, codeine) without a prescription or without a doctor telling you to do so?". In the report, the investigators stated that "this item was intended to inform on students' use of opiate medication for recreational purposes. An estimated $20 \%, 18 \%, 17 \%$ and $19 \%$ of students in Nova Scotia, New Brunswick, Newfoundland and Labrador, and Prince Edward Island respectively responded in the affirmative to this item", and the authors concluded "It is clear from these results that the 2007 question tapped into the use of opiates for pain and does not have face validity as an item on opiate use for recreational purposes" (5).

These rates are consistent with Canadian statistics regarding the prevalence of chronic pain, which is estimated to be $18.5 \%$, with rates being higher in women and increasing with age $(23.9 \%$ to $31.3 \%$ in individuals 65 years of age or older) (6). The prevalence of chronic pain is high; when opioid use for acute pain related to injury or surgery and for cancer pain is added to this, the requirement for opioids to treat pain is significant.

The literature presented above indicates that approximately $20 \%$ of Canadians 15 years of age and older are using POAs, and this figure dropped to $16.7 \%$ in 2011 . The studies involving students have found that $17 \%$ to $20 \%$ of students in grades 7 through 12 are using POAs without a prescription, and most obtained the POA from a friend or family member. The Student Drug Use Survey in the Atlantic Provinces (5) acknowledged questions regarding use without a prescription tapped into use for pain.

South of the border, the United States National Survey of Drug Use and Health 2011 (7) is a nationwide survey of residents in noninstitutional households 12 years of age and older. Nonmedical use is defined as use without one's own prescription or simply for the experience or feeling the drug caused. The most recent survey reports that the rate of nonmedical use of pain relievers declined among youth 12 to 17 years of age, from $3.2 \%$ in 2002 to $2.3 \%$ in 2011 . In young adults (18 to 25 years of age), the rate of current nonmedical use of pain relievers in 2011 was $3.6 \%$, lower than the rates in 2002 through 2010 (eg, $4.1 \%$ in $2002 ; 5.0 \%$ in $2006 ; 4.4 \%$ in 2010). Approximately $2 \%$ of individuals 12 years of age or older report the nonmedical use of pain relievers. Over the past decade, this rate has hovered in the $1.9 \%$ to $2.1 \%$ range and dropped to $1.7 \%$ in 2011 . Most (54.2\%) had received the medication from a friend or relative for free. Several United States studies have examined the motivation for NMPOU and have found that the single leading reason was for relief of pain $(8-10)$.

\footnotetext{
Department of Psychiatry 83 Anaesthesiology, Dalhousie University, Queen Elizabeth Health Sciences Centre, Halifax, Nova Scotia Correspondence: Dr Mary Lynch, Department of Psychiatry $\mathcal{E}$ Anaesthesiology, Dalhousie University, Queen Elizabeth Health Sciences Centre, Halifax, Nova Scotia B3H 1V7. Telephone 902-473-6428, fax 902-473-4126, e-mail mary.lynch@dal.ca
} 
For a more comprehensive perspective, it is also instructive to examine the literature on illicit use of substances in general. According to the CADUMS highlight report 2011, the individual rates of use of illicit substances other than cannabis, such as cocaine or crack, amphetamines, hallucinogens, ecstasy and heroin, was reported by $1.7 \%$ of Canadians, with a higher rate in males $(2.4 \%)$ than females $(1.0 \%)$ and a higher rate in youth $(4.8 \%)$ than adults $(1.1 \%)$. This was a statistically significant decrease from 2004, when the rate was 3.0\% overall and $11.3 \%$ in youth.

In the United States in 2011, 20.6 million individuals (8.0\%) 12 years of age or older were classified with substance dependence or abuse in the past year, based on criteria specified in the Diagnostic and Statistical Manual of Mental Disorders, 4th edition. Between 2002 and 2010, the number of individuals with substance dependence or abuse was stable, ranging from 21.6 million to 22.7 million; thus, there was a decrease in the rates of substance abuse and dependence in 2011 (7). The situation is similar in Canada.

\section{REFERENCES}

1. Shield KD, Jones W, Rehm J, Fischer B. Use and nonmedical use of prescription opioid analgesics in the general population of Canada and correlations with dispensing levels in 2009. Pain Res Manag 2013;18:69-74

2. Health Canada, 2011. Canadian Alcohol and Drug Use Monitoring Survey (CADUMS) highlight report 2011. <www.hc-sc.gc.ca/hc-ps/ drugs-drogues/stat/_2011/summary-sommaire-eng.php> (Accessed February 15, 2013)

3. Paglia-Boak A, et al. Drug Use Among Ontario Students 19772009. CAMH Research Document Series 2009. Centre for Addictions and Mental Health, 1-227.

4. The Alberta Youth Experience Survey 2008: Technical Report. Alberta Health Services Addiction and Mental Health, Edmonton, Alberta 2009, 1-267.

5. Poulin C, Elliott D. Student drug use in the Atlantic provinces, 2007: Atlantic technical report. Halifax: Dalhousie Community Health and Epidemiology, 2007.

6. Reitsma ML, Trammer JE, Buchanan DM, Vandenkerkhof EG. The prevalence of chronic pain and pain related interference in the Canadian population from 1994 to 2008. Chronic Dis Inj Can 2011;31:157-64.

7. Results from the 2011 National Survey of Drug Use and Health, Summary of National Findings in NSDUH Series H-44, 2012, Substance Abuse and Mental Health Services Administration:

\section{SUMMARY}

The evidence from high-quality nationwide Canadian surveys indicates that NMPOU is decreasing, and the use of POAs to get high is in the range of $0.4 \%$ and decreasing. Shield et al (1) found no association between the misuse of POAs and the general use of POAs. It has also been determined that most of the individuals who are using opioids 'nonmedically' are actually using them for the treatment of pain and have obtained the medication from a friend or family member. There have been similar trends in the United States. There has also been a significant decline in the use of illicit substances in general, as well as a decline in the rates of substance dependence and abuse. It is important to remember these facts as we interpret the continuous stream of data-mining studies on the topic of NMPOU (11-13). Now that we have a greater understanding that most NMPOU is an attempt to treat pain, it is important to develop policies to address the issue of the undertreatment of pain in Canada. For this, we need a national pain strategy (14).

Rockville, MD. <www.samhsa.gov/data/NSDUH/2k11Results/ NSDUHresults2011.htm > (Accessed February 15, 2013)

8. McCabe SE, Cranford JA, Boyd CJ, Teter CJ. Motives, diversion and routes of administration associated with nonmedical use of prescription opioids. Addict Behav 2007;32:562-75.

9. McCabe SE, Boyd CJ, Cranford JA, Teter CJ. Motives for nonmedical use of prescription opioids among high school seniors in the United States: Self treatment and beyond. Arch Pediatr Adolesc Med 2009;163:739-44.

10. Boyd CJ, McCabe SE, Cranford JA, Young A. Adolescents' motivations to abuse prescription medications. Pediatrics 2006;118:2472-80.

11. Dhalla IA, Mamdani MM, Gomes T, Juurlink DN. Clustering of opioid prescribing and opioid related mortality among family physicians in Ontario. Can Fam Physician 2011;57:e92-6.

12. Gomes T, Juurlink DN, Dhalla IA, Mailis-Gagnon A, Paterson JM, Mamdani MM. Trends in opioid use and dosing among socioeconomically disadvantaged patients. Open Med 2011;5:213-22.

13. Dhalla IA, Mamdani MM, Sivilotti ML, Kopp A, Qureshi O, Juurlink DN. Prescribing of opioid analgesics and related mortality before and after the introduction of long-acting oxycodone. CMAJ 2009;181:891-6.

14. Lynch ME. The need for a Canadian pain strategy. Pain Res Manag 2011;16:77-80 


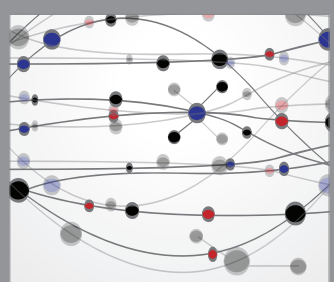

The Scientific World Journal
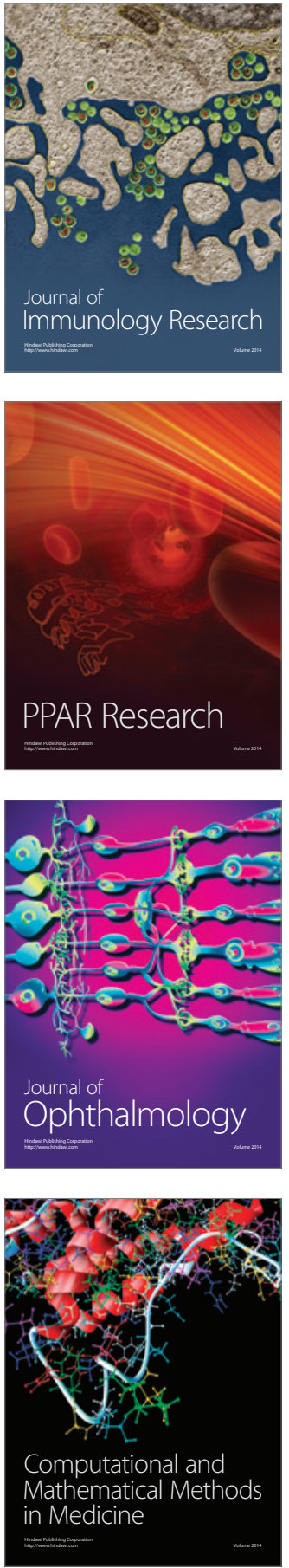

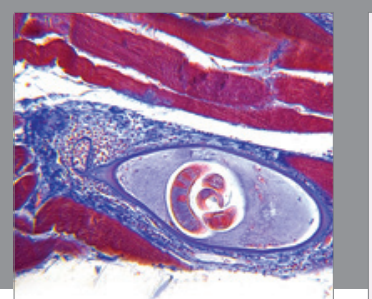

Gastroenterology Research and Practice

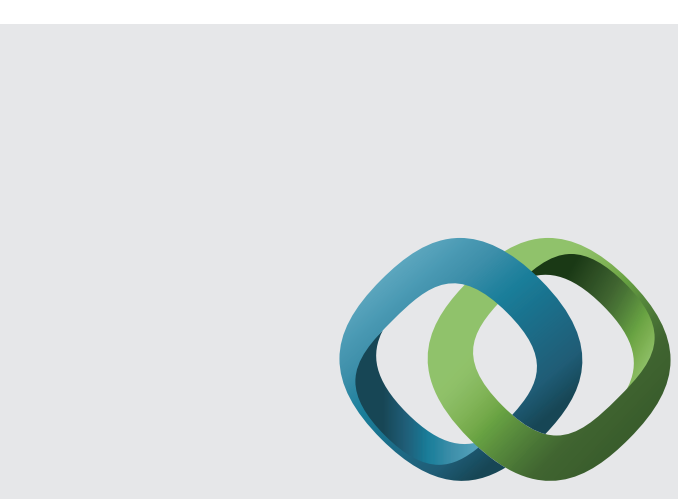

\section{Hindawi}

Submit your manuscripts at

http://www.hindawi.com
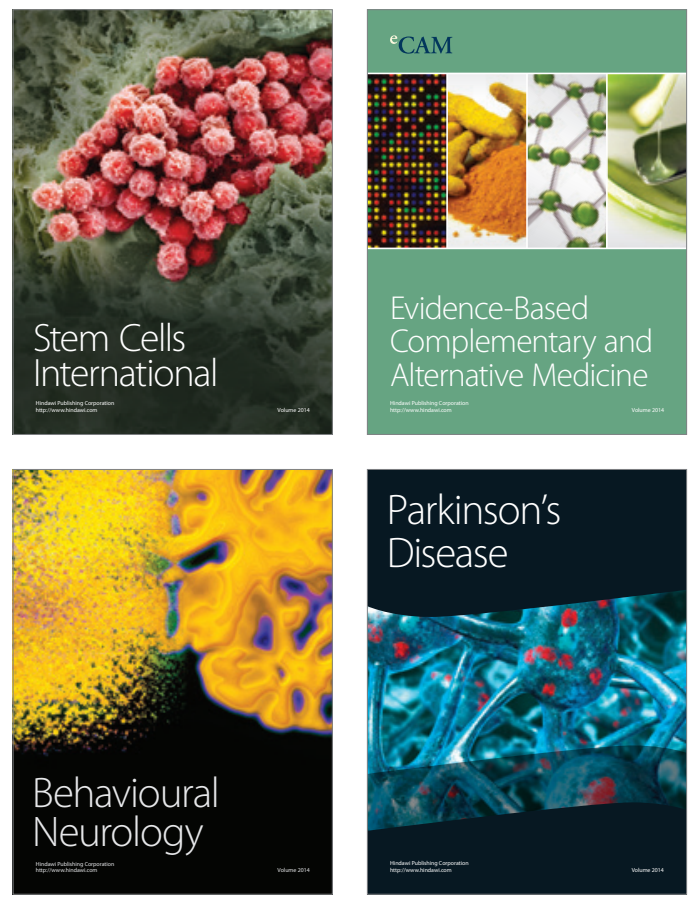
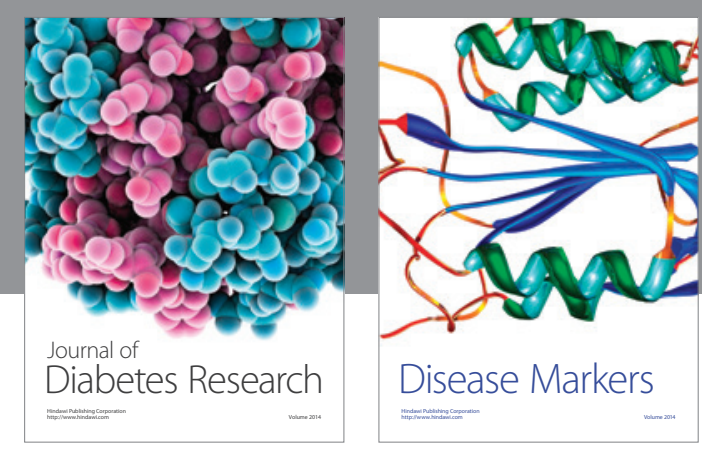

Disease Markers
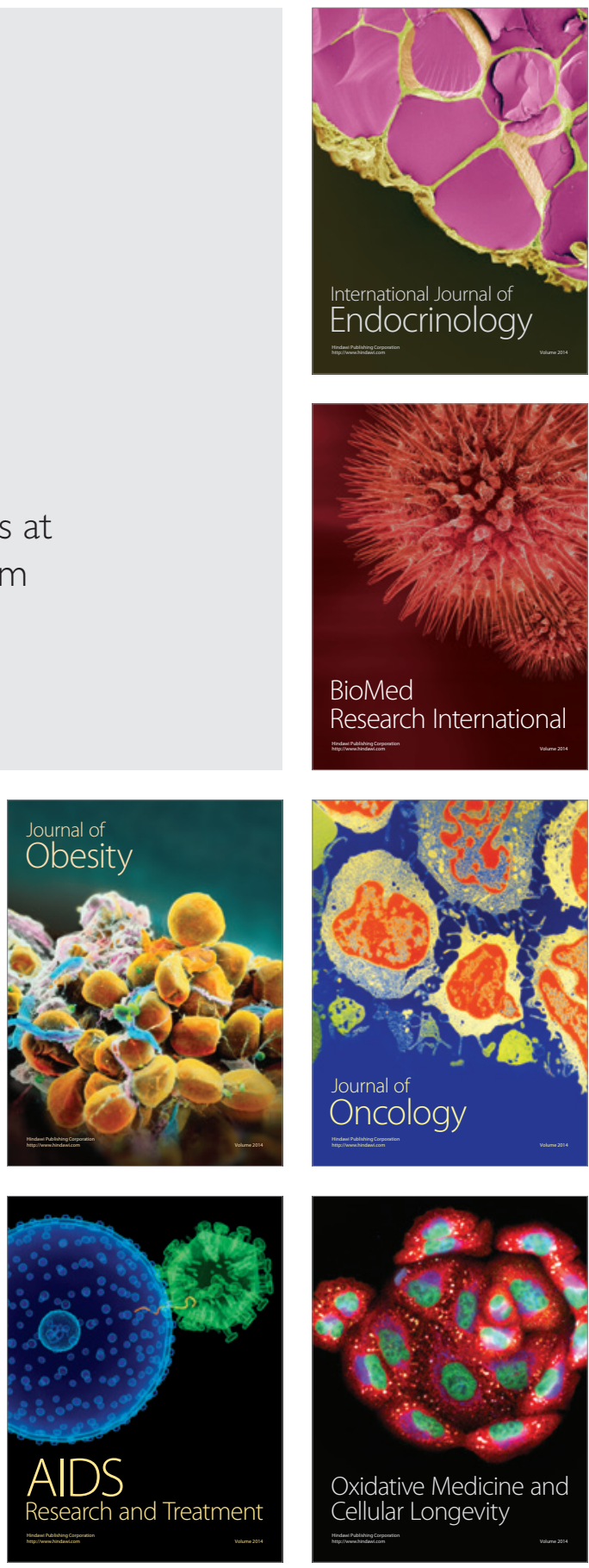